\title{
The importance of adaptive expertise in CAD learning: maintaining design intent
}

\author{
Basilio Ramos Barbero, Carlos Melgosa Pedrosa and Gabriel Castrillo Peña \\ Graphic Expression Department, Escuela Politécnica Superior, Universidad de Burgos, Burgos, Spain \\ To cite this article: Basilio Ramos Barbero, Carlos Melgosa Pedrosa \& Gabriel Castrillo Peña (2018) The \\ importance of adaptive expertise in CAD learning: maintaining design intent, Journal of Engineering Design, \\ 29:10, 569-595, DOI: 10.1080/09544828.2018.1519183
}

\begin{abstract}
In CAD modeling, there is no one general standardized teaching-learning methodology. We use the strategic-learning methodology, maintaining design intent, fully aware that it is necessary to modify CAD models for their reuse. Questions concerning the thought processes of students when modeling with CAD and the strategies that they choose that best maintain design intent arise in the course of using the 3D modeling programs. Our aim here is to determine the importance of adaptive expertise in the results of CAD models and, particularly, in one of its constructs: design intent. To do so, CAD-based experimentation took place over two years with 78 third-year students in the first year and with 53 third-year students in the second year from the subject module of Graphic Engineering, on the Degree in Mechanical Engineering of the University of Burgos. At the start of the year, the students conducted a survey to measure adaptive expertise. Subsequently, in the first year of experimentation, the students prepared various CAD models and the design intent was evaluated in one of them (a connecting rod or conrod), broken down into the skeleton, the structure, the modifications and the constraints. In the conrod exercise, the students also completed a questionnaire both before and after designing their models, which were analyzed to detect the thought processes and the strategies that they had applied. In the second year of experimentation, design intent was incorporated in various exercises at the beginning of the year, in addition to the conrod. The main conclusion is that the correct division of the part into its pieces and adaptive expertise improved the results in relation to design intent in the CAD.
\end{abstract}

KEYWORDS: CAD learning; design intent (DI); adaptive expertise (AE); modification of CAD.

\section{INTRODUCTION}

In 2010, the concept of the Model-Based Enterprise (MBE) emerged in the United States (Contero). The reuse of CAD models is at the core of the MBE concept (Camba et al. 2014). This reuse is based on two ideas: that CAD 3D models can be modified throughout the whole product life-cycle and that these models are the starting point of new models that will in turn be modified. If CAD models are easy to reuse, then the benefits derived from these models will be greater. To do so, the condition is that other people must find the methodologies for their production easily understandable and must be able to alter these models easily; a condition that is frequently not satisfied. In this context, one critical aspect of the reuse of CAD models is the identification and comprehension of the Design Intent (DI) of the model, which in general is implicitly expressed in the CAD model. DI expresses the reasons that motivate a designer to perform some specific CAD modeling actions. It also expresses the manner in which the designer expects the geometric model to behave when it is modified (Alducin-Quintero et al. 2012). Unfortunately, modifications of 
industrial CAD models are in many cases difficult or almost impossible to apply at present (Salehi and McMahon 2009).

On that basis, Mandorli and Otto (2013) affirmed that current educational methods should focus more on strategic knowledge to deepen the understanding of students, so as to enable them to use CAD systems as knowledge-intensive design and communication tools, to develop DI, and to convey it properly. At present, CAD methodology is principally based on: parametric design, feature modeling, the use of the tree and the parent-child relations of feature dependence. According to Otey et al. (2014), there is a consensus that modeling tools and strategies greatly influence DI.

In $\mathrm{CAD}$, there are often various ways of generating a feature, for example, a thru-hole may be executed by means of: 1) a cutting revolution; 2) a pocket of a circle; 3) the 'hole' command; 4) a Boolean operation where a solid cylinder is subtracted; and, 5) any other methods. This variety of options for feature generation requires additional effort from the CAD designer, as the designer should know the different alternatives and should understand how to choose the suitable alternative. Bhavnani, Reif, and John (2001) expressed agreement on this point, in so far as this knowledge is not learnt through command-based instruction, but he also stressed the importance of familiarization with different alternative methods and of knowing how to choose wisely between them when computer tools are complex and offer many alternatives.

It has been proven that different students, with different CAD-related skills, model the same CAD models, in a valid way with different methods. However, some CAD models maintain the DI and are flexible and robust when the functional parameters are modified, unlike other models. Chester (2007) therefore proposed CAD learning that fosters the skills of selecting the appropriate combination of CAD principles and design rules to solve problems. Case-based learning of strategic knowledge should be employed instead of merely learning commands. Strategic knowledge is related to knowledge of alternative methods by which a task may be done and what the correct process is for that task to be carried out. It is necessary to establish the thought processes of students when they design the CAD models, to know why the students employ certain strategies, and to value whether certain thought processes yield better or worse results in terms of DI.

We used a tool proposed by Peng et al. (2014) (annex 3), in order to assess the thought processes of students while modeling. It involves the administration of a questionnaire before and after designing a CAD model, in which the students are asked about the strategies that they would use before designing the CAD models and for the proposed strategies after completing the CAD models. Basically, the idea of this questionnaire is to detect which of the strategies that the students employ will yield the best results for DI when the part is modeled.

The students are expected to become experts in the use of CAD, developing the capability to adapt to changes and software innovations. We therefore seek to establish whether both CAD learning and one of its constructs, DI, have relations with Adaptive Expertise (AE) and with the thought processes of students when modeling a part in CAD. AE is understood, in general terms, by the facility to solve new problems on the basis of earlier experiences. Hence, the use of the survey of AE proposed by Peng et al. (2014) (annex 1), with the aim of identifying whether students with 
greater AE will obtain better results for DI and therefore better results for CAD. According to Fisher and Peterson (2001), AE may be measured by four constructs: multiple perspectives, metacognition, goals and beliefs, and epistemology. These qualities may be measured with the survey used by Peng et al. (2014) in annex 1. As those results between AE and DI were not generally significant in the first year, the experimental procedure was repeated for a second year, this time using the complete 42-item Fisher survey (Fisher and Peterson 2001) (annex 2), from which Peng et al. (2014) derived the survey of 17 items.

The constructs of AE may also be identified in accordance with the responses given by students to the questionnaire used by Peng et al. (2014) in annex 3, where the responses given by the students to the open questions, both before and after completing the modeling of the part in question, permit the classification of students according to whether or not they possess AE qualities. This methodology has been used by Liu et al. (2015) and therefore, in another part of the study, the question of whether AE qualities are related with DI in CAD will be checked. Modifications of various functional parameters were introduced to the CAD models that the students had designed, to identify which students correctly transferred DI in CAD.

In summary, the investigation seeks to understand the thought processes of students when modeling a part in CAD; to know whether AE helps to improve the CAD results; and to know whether AE helps to express DI.

\section{RELATED WORK}

The key to a well-designed CAD model is that it may be reused (Camba et al. 2014) and therefore modified. The modifications of the functional parameters of the CAD pieces should give the expected results and maintain the DI. The DI is achieved if the function of the part is known, and if the student who designs the CAD model is familiar with different methods of modeling and knows how to choose correctly between them. We believe that AE helps to select the most suitable method for CAD modeling. Therefore, in this section, a study is completed of the works that relate $\mathrm{DI}$ in $\mathrm{CAD}$ and $\mathrm{AE}$ in CAD.

The first element, DI in CAD, is achieved through the design structure, in other words, through the sketch or croquis, the constraints, the parameters, the skeleton, the operations, etc., where a flexible and robust design maintains the DI when it is modified. The flexibility permits changes to be introduced in the structure of the model and robustness is achieved, if it offers the expected results when subjecting that model to any type of change. Therefore, not only is the final result important, but so too is the design process, which is largely responsible for the flexibility and the robustness of the model or the absence of those qualities.

Although there is no standard definition of DI in CAD, many authors have sought to define this term:

- For Otey et al. (2014, 2018), DI is a term that is commonly defined as the expected behavior of a CAD model after undergoing a modification. 
- $\quad$ Rynne and Gaughran (2008), defined DI as a description of how an object is modeled and also how it should perform once altered.

On the basis of surveys administered to industrial experts, Bodein, Rose and Caillaud (2013) affirmed that it is fundamental to comply with the DI to be able to reuse a CAD model. The aforesaid DI is necessary, so that the modifications in the models may be completed, as despite the advances in CAD technology, it is difficult or impossible to reuse the model without the DI, be it through parameters, constraints, etc. (Salehi and McMahon 2009). With this same idea in mind, Hofmann et al. (2018) affirmed that 3D models are in general not reusable, perhaps due to the advanced skills that $3 \mathrm{D}$ modelling requires, despite $56 \%$ of such models having been reused at least once. It is very important to use functional geometry objects that capture the DI so that the models are reusable.

According to Yang and Han (2006), between one third and half of the quality problems in models can be traced back to poor design skills and the inexperience of the designer. In addition, Jackson and Buxton (2007), on the basis of survey results, detected that the reuse of models is difficult in many firms, as those modifications require a highly developed knowledge of CAD (57\%), the models are inflexible and fail after completing the changes (48\%), or because only the designers themselves are capable of successfully introducing the changes in their models (40\%). Ye et al. (2004) carried out studies on firms to evaluate CAD education in universities in accordance with the knowledge of their workers. Their surveys with $74 \%$ of participants indicated that the command-based teaching methods are inappropriate, which points to the importance of centering on the concept of DI.

Chester (2007) proposed that learning should be exclusively strategic, without combining it with command-based learning, as strategic learning is the most appropriate for compliance with DI. In a study divided into two parts (Hartman 2004, 2005), Hartman sought to determine how expert designers in the firm achieved their level of CAD knowledge, and stated that CAD learners should carry out practices from the start where they create and alter the models that they design.

Ramos, Melgosa, and Zamora (2017) compiled a set of summary rules, which must be taken into account when choosing a modeling path in CAD, so as to transfer DI in the modeling of 3D parts. The summaries of the skeleton, the structure, the modifications, and the constraints on the sketches that were employed improved the learning of 3D design in a statistically significant way. That improvement was especially noted in the concepts of skeleton creation that included the DI, in the functional division of the part as per the design process, and in the constraints on the sketches.

Otey et al. (2018) completed a review of DI in CAD teaching and affirmed that enhancing the DI that is conveyed through CAD models may be performed at three different levels (sketch constraints, relations between modelling operations, and the modelling operations themselves). Research has shown that rubrics can be a useful tool to facilitate standardized DI communication. Rubrics are not only important for assessment, but also for the communication of expectations. Company et al. (2017) proposed the following three principal blocks to measure DI by means of a 
rubric: 1) the model tree can be likened to a 'script' that describes the elements that constitute the part and its functionality; 2) the modelling was done in such a way as to avoid the loss of design information; and, 3) the model was simultaneously flexible and robust. The inclusion of a modification of a dimension, shape, or operation within a rubric with which the student was previously familiar facilitated the comprehension of the DI.

The modifications must be introduced in the sketches, the planes, or the features of the tree in 2D and cannot be introduced in 3D, as Mandorli, Otto, and Raffaeli (2016) also affirmed. There is a new CAD modeling methodology called Direct Model that is similar to feature modeling, but without a history tree; it permits easy modification of the model in 3D by means of push and pull commands on points, lines, and faces. But Bodein, Rose, and Caillaud (2014) indicated that the use of the direct modeling system in industry is currently limited to the initial phases of the projects (conceptual phases and initial prototypes) and that the information is afterwards transmitted to the CAD packages with history tree and features methodology. Despite the advantages that it allows of rapidity, few constraints, and ease of modification, the direct modeling methodology does not permit the integration of knowledge, parametrization, standardization, and the definition of restrictions on entity, relations, and dependencies; in other words, modifications that maintain the design intent are not permitted.

As regards $\mathrm{AE}$ in $\mathrm{CAD}$, the second element of this study, few studies in the literature have examined expertise in CAD modeling procedures. Among the different types of methodology for the learning of CAD 3D modeling, for Peng et al. (2014), the important point is the learning of CAD skills, which can be used whichever the software modeling package. This point is one of the reasons for the importance of AE in students, as command-based learning refers to a particular software package.

$\mathrm{AE}$ is the term that defines the capability of being both innovative and adaptive to new challenges while also having content knowledge associated with expertise (McKenna 2007). In other words, it is the skill of applying and adapting knowledge, when confronting new situations, normally those in which there is a certain absence of knowledge (Salehi and McMahon 2011).

Students will have to solve a great variety of problems, hence the importance of AE in detriment to routine expertise, as according to Hatano and Inagaki (1986), students with AE are capable of developing procedures in an effective way, allowing them to solve problems in an innovative manner (Brophy, Hodge, and Bransford 2004).

Peng et al. (2014) put the survey by Fisher and Peterson (2001) into practice to analyze AE for CAD exercises. In addition, he conducted some interviews before and after completing the design of an in-context exercise. The responses were analyzed to classify his students in each one of the four constructs of the AE. Those interviews were used in our study in the form of questionnaires.

According to Fisher, the four constructs of AE are (Fisher and Peterson 2001):

- Multiple perspectives: referring to the willingness to use a variety of approaches when working on a problem (Fisher and Peterson 2001). This variety means that there may be more than one way of finding the solution to a problem and, therefore, those students that 
present this quality are open to receiving new information and to applying it to new situations that require innovation (Fisher and Peterson 2001).

- Metacognition: the capability that we have as people to self-regulate our own learning, in other words, to plan which strategies have to be used in each situation, to apply them, to control the process, to detect possible failures... and to transfer all of it into a new learning situation (Aldaz Herrera 2006). Thus, the student can identify areas in which their knowledge can be improved (Fisher and Peterson 2001).

- Goals and beliefs: describe the viewpoints of the students with regard to their learning goals and the nature of the knowledge. The students that present this quality see the challenges as an opportunity to improve and are capable of continuing with the exercise despite the uncertainty (Fisher and Peterson 2001). Self-regulation strategies help to identify the goals that generate ideas or improve an existing idea (McKenna 2007).

- Epistemology: refers to how students behave when faced with the nature of knowledge. Students who demonstrate epistemological attributes perceive knowledge as an evolving rather than as a static entity, so they are aware of the need to practice their knowledge regularly (Fisher and Peterson 2001).

Nevertheless, the objectives that other authors such as Peng et al. (2014) pursued through the survey and the pre- and post-modeling questionnaires before and after the CAD modeling of the parts, which we also make use of in our study, differed from our own objectives. They search for the differences in qualities of the AE in demographic questions (gender, age...) and the experience that the students have with CAD (freshmen, sophomores and seniors) in terms of time.

Fisher and Peterson (2001), the authors of the AE survey used in this study, also applied it with different objectives in another branch of knowledge: biomedical engineering. On that occasion, they were attempting to quantify the acquisition of $\mathrm{AE}$ constructs through those university studies and to find out how to develop them.

The same pre- and post-modeling questionnaires of Peng et al. (2014) before and after the modeling of the parts were also used by Ke Liu et al. (2015) in interviews; who classified the responses given by students to ascertain their AE, searching for:

- Efficiency (consistency \& accuracy), innovation, flexible responses to novel situations in the Multiple Perspectives dimension.

- Confidence, successfully monitor own understanding, recognize that one's own knowledge may be incomplete, and use different/multiple methods to solve problems, in the Metacognition dimension.

- Opportunities for new learning and self-regulation strategies, in the Goals \& Beliefs dimension.

- The pursuit of knowledge in practice, leaving others to provide information in the Epistemology dimension.

Liu et al. (2015) stated that: correct use of the origin; greater use of matrices, patterns and reference geometry; and the correct selection of the sequence of features are strategies that improve AE. This work is the most recent one to have related DI in CAD with AE.

Among the works mentioned above, very little empirical work has been done to examine the role of $\mathrm{AE}$ in relation to $\mathrm{CAD}$ modeling. 


\section{RESEARCH METHODOLOGY}

Having taught the new Graphic Engineering module on the Degree in Mechanical Engineering at the University of Burgos over four years, the need has arisen to understand which qualities the students present that are conducive to better learning. There is in consequence a need to determine which aspects those students take into account that better express DI in their CAD exercises

In line with that aim, at the start of the academic year, the students completed a survey on their AE adapted to the context of CAD (annex 1). Devised by Fisher and Peterson (2001) the survey contains 42 questions for engineering students of biomedical engineering, approximately half of which are in the negative. Subsequently, Peng et al. (2014) adapted this survey to 19 questions, for the completion of CAD exercises in context, where other questions were also included, inquiring into any previous experience of the students with $\mathrm{CAD}$, engineering, and manufacture. In this study, the surveys in annexes 1 and 2, adapted to the modified Likert scale, with 6 values, were used to counter the tendency among students to assume a neutral stance. Students with previous knowledge of CAD were identified, who had worked with industry or mechanics and had knowledge of manufacturing processes, which in our opinion can be related with DI (annex 1).

Liu et al. (2015) also employed the questionnaire designed by Peng et al. (2014) that is divided into two sections: one section before the modeling of a part and another section after completing the part (annex 3). The object of this questionnaire is to know what the students think when they are engaged in modeling a component in CAD and to identify the AE of each student in accordance with their responses to the open questions. In our work, the questionnaire in annex 3 was also used to divide the students into two groups (students with and students without AE abilities or with some of its aspects: multiple perspectives, metacognition, goals and beliefs, and epistemology), to test whether there is a relation between $\mathrm{AE}$, or at least some of its constructs, and the learning of $\mathrm{DI}$ in CAD.

The questions in annex 3 are grouped under the following headings:

- Proposal for the modeling: a matter of identifying the most important concepts to consider before the part is modeled. It is one of the rules referring to the reuse of CAD designs proposed by Bodein, Rose, and Caillaud (2013).

- Familiarity with the object: with these questions, the aim is to establish the importance of familiarity with the parts that will be modeled when carrying out flexible and robust design.

- $\quad$ Changes in case of repeating the modeling of the part: in this phase, the question of whether compliance with DI has really been achieved is evaluated and how to improve the model in case of not having complied with its DI.

- Difficulties: the expected difficulties and the ways students think they can surmount them are identified; as well as the difficulties that they finally have and how these may be solved. In this way, the necessary information is collected, so that future students are familiar with the strategies that help to surmount some of the problems.

- $\quad$ Time spent thinking and modeling the part: a relation between the time spent thinking and the completion of the part with its respective grade. 
Analyzing the responses, the work of each student is classified by the four qualities of AE and how many of those qualities they present. With this analysis, the aim is to establish the importance of $\mathrm{AE}$ in relation to the correct inclusion of DI in the 3D modeling and, particularly, to identify which of the 4 parameters is more advantageous or influential.

The classification of the responses given by the students in the survey of annex 3, under some of the AE constructs, is based on the codes given by Liu et al. (2015). For example: 1) to think of the most efficient or easiest way of making a model are two indicators of multiple perspectives; 2) complexity of the objects and having to pay close attention while modeling are two indicators of metacognition; 3) to know what steps to take first, to have a good starting point, and to have strategies to model are indicators of Goals \& Beliefs; and, 4) to practice, reading more, and to request assistance from someone else are indicators of epistemology. Although we base our work on the codes used by Liu, students may in practice present these in different ways. Therefore, when completing the analysis of the responses from a student, rather than subjecting each response to a list of codes through which the student may be categorized, the analyst has previously internalized the 4 concepts of adaptive expertise (thanks in part to their having read the codes used by Liu) and creates the list of codes as long as he analyses the responses of the students. Some examples of the classification of the responses given by our students can be seen in section 4.4 of this article. A student possesses one of the 4 constructs of $\mathrm{AE}$ if an indicator of that construct is identified in the responses given in annex 3 , converting a qualitative response into a quantitative one when awarding 1 if the student possesses the construct and 0 if otherwise. A mixed analysis is therefore done of $\mathrm{AE}$ and the responses of the student can show evidence of $0,1,2,3$, or 4 constructs of AE.

The modeling of a part in CATIA software, the simplified connecting rod (conrod) of a motor, was proposed, to test the DI of the CAD models that the students prepare, as the students relate the form of the part with its function (Fig. 1). Bodein, Rose, and Caillaud (2014) proposed that the preliminary task, before a valid and functional CAD model is obtained, is to identify the suitable functional parameters of the requirements. Hence, some functional parameters are modified, in order to evaluate the result of CAD and $\mathrm{DI}$ in CAD, thereby confirming the flexibility and robustness of each CAD model in accordance with the result of each modification. The students have a neutral format 3D model to take the measurements that they consider advisable. They model the conrod in the first weeks of the course, after having studied the DI rules given in Ramos, Melgosa, and Zamora (2017) for solid modeling.

The following aspects of the conrod were evaluated: the design (similarity of form with the real model and that two functional dimensions are correct in the model), the tree (if the part has a skeleton, the pieces which constitute the part and their correct names for easy identification of the different parameters, and the use of Boolean operators), and the DI modifying certain functional dimensions (see Fig. 2). The modifications are: the distance between axes in the conrod (dimension 170), the dimension of the diameter of the hole that is linked to the crankshaft (dimension D30), the distance between the axes of the bolt holes through which the bolts are inserted to attach the conrod to the crankshaft (dimension 50); and the thickness of the web of the rod. The grades were out of a total of 10 points: 3 points for the design of the part (1 point for the form of the part and 2 points for confirmation of the value of two dimensions); the tree had 3 points where the scores 
were for: the skeleton (1), appropriately naming the different tree branches (1), having pieces and Boolean operations (1); and 4 points for DI (4 dimensions were modified, awarding 1 point for each modified dimension that maintains the design intent).

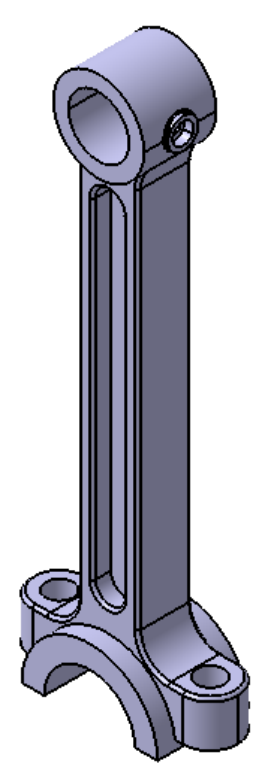

Fig. 1. Model of the conrod in the stp format

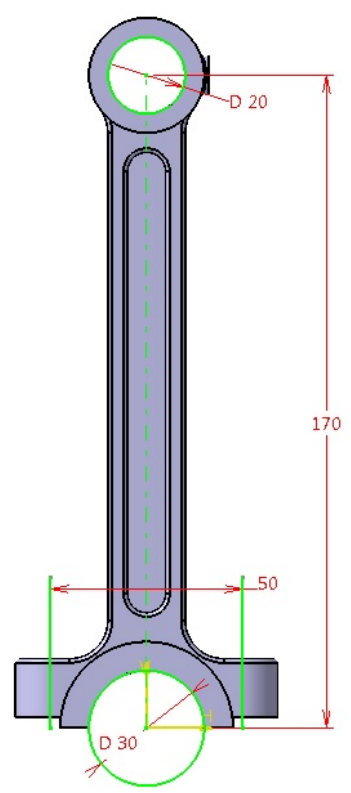

Fig. 2. Functional dimensions of the conrod

Some examples where the DI is maintained when modifying these dimensions may be seen in figure 3 .

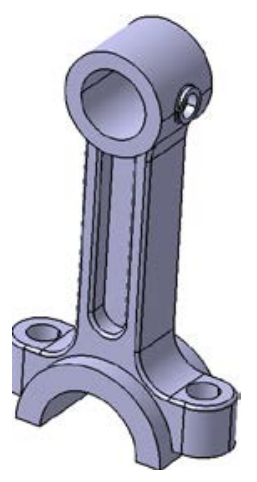

a

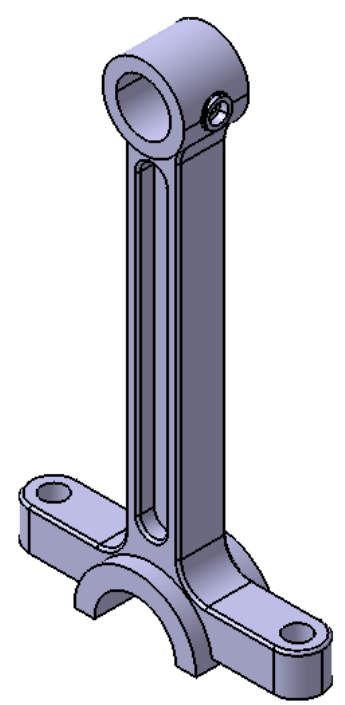

b

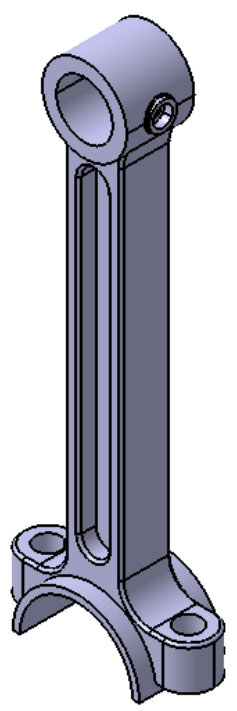

C

Fig 3. Modification of the functional parameters of the conrod. a) dimension 170; b) dimension 50; c) dimension D30

With the objective of improving the results, the experimental procedure was repeated in a second year, but using the complete survey of Fisher and Peterson (2001) (annex 2), instead of the survey of Peng et al. (2014) (annex 1) and DI was introduced at the beginning of the year. Greater numbers of exercises were completed and evaluated, in addition to the conrod, taking DI into account. In fig. 4, the models of an elbow, a mold, and a T-connector are shown, where the function, the parametrization and the skeleton have to be taken into account, among other properties. 


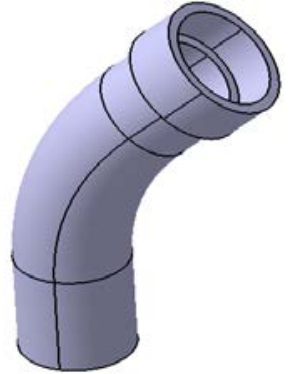

a)

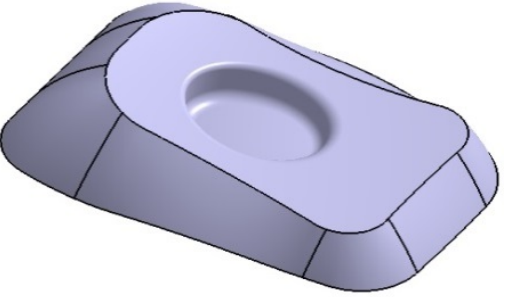

b)

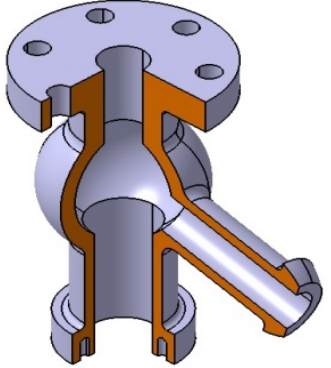

c)

Fig. 4. Models of: a) elbow, b) mold and c) T-connector

In consequence, the design of various parts and the modifications of their functional parameters were used to evaluate the DI in the CAD model, the survey in annex 1 and 2 was used to assess the AE of students, based on their self-evaluations, and the questionnaire in annex 3 was used to ascertain the different aspects of the thought processes of the students when modeling in CAD and to classify the AE of the students, in accordance with the responses to the open questions in that questionnaire. As well as the design of the conrod, the students perform other 3D practices and learn a set of CAD modeling rules in the theoretical classes. In the study, the average student grades are also taken into account in all of the practical exercises and in the theory classes, with the aim of testing whether significant relations exist with the AE constructs.

\section{RESULTS AND THEIR ANALYSIS}

With the object of gaining a general overview of student grades for $\mathrm{CAD}$, $\mathrm{DI}$ and $\mathrm{AE}$, the histograms of the conrod design, the average grades for the practices, the theory, the AE surveys jointly over both years, and DI in the second year, are all included in the histograms in figure 5.
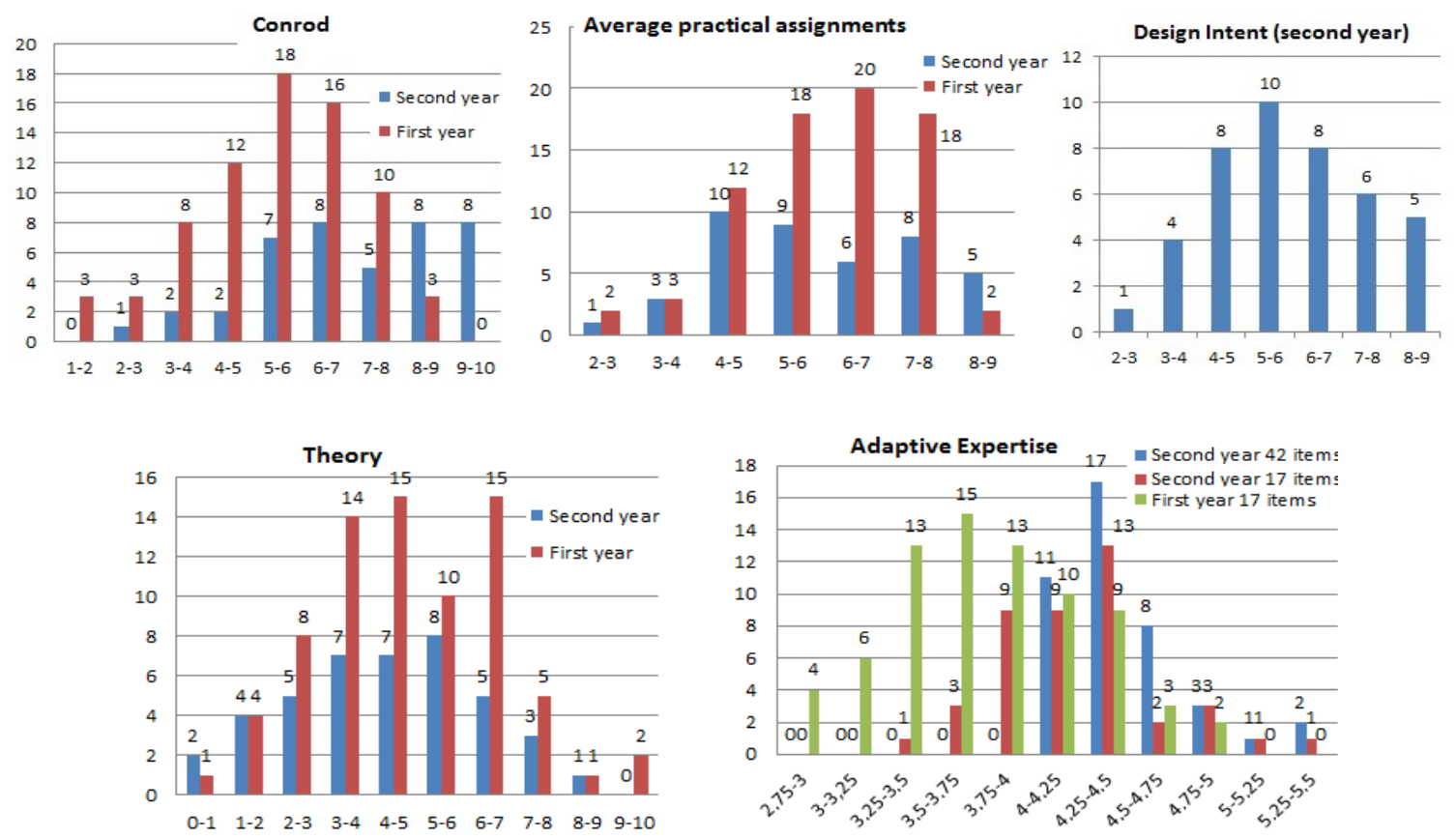

Fig. 5. Histograms of the grades.

It may be said that the results in the second year for the conrod design were better than those of the first year, as the students had more time to complete that exercise. The average AE grade was 3.78 points with 17 items in the first year, lower than the average grade of 4.45 points with the $42-$ 
item survey in the second year. And if we were only to evaluate 17 of the 42 items from annex 2 in this second year (which coincide with annex 1), then the average would be 4.21 points. This result leads us to suppose that the $\mathrm{AE}$ of the group of (third-year) students in the first year was less well developed.

In a second general study, we sought to establish the degree to which AE (and its constructs) were related with DI and knowledge of CAD. We conducted non-parametric bivariate correlation analyses to do so (Spearman's rho), given that some of the variables were not normally distributed (table 1 for the first year and table 2 for the second year)

Table1. Correlations in the first year

\begin{tabular}{|l|l|c|c|c|}
\hline \multicolumn{2}{|l|}{ Spearman's rho } & $\begin{array}{c}\text { Grade for the } \\
\text { Conrod }\end{array}$ & $\begin{array}{c}\text { Grade for } \\
\text { Theory }\end{array}$ & $\begin{array}{c}\text { Average grade practical } \\
\text { assignments }\end{array}$ \\
\hline Adaptive Expertise & Correlation & 0.062 & 0.064 & 0.113 \\
& Sig. (2-tailed) & 0.605 & 0.585 & 0.383 \\
\hline Multiple Perspectives & Correlation & 0.010 & $-0.247^{*}$ & -0.188 \\
& Sig. (2-tailed) & 0.934 & 0.033 & 0.144 \\
\hline Metacognition & Correlation & 0.145 & $0.391^{* *}$ & $0.369^{* *}$ \\
& Sig. (2-tailed) & 0.220 & 0.001 & 0.003 \\
\hline Goals and Beliefs & Correlation & -0.039 & 0.045 & 0.093 \\
& Sig. (2-tailed) & 0.742 & 0.703 & 0.471 \\
\hline **. Correlation is significant at 0.01 (2-tailed). \\
*. Correlation is significant at 0.05 (2-tailed).
\end{tabular}

In the first year, a linear relation was observed in the results of the 17-item survey between the construct Metacognition and grades for theory and average grades for practical assignments, and between Multiple Perspectives and grades for theory.

Table 2. Correlations in the second year

\begin{tabular}{|l|l|c|c|c|c|}
\hline \multicolumn{2}{|l|}{ Spearman's rho } & $\begin{array}{c}\text { Grade for } \\
\text { the Conrod }\end{array}$ & $\begin{array}{c}\text { Grade for } \\
\text { Theory }\end{array}$ & $\begin{array}{c}\text { Average grade } \\
\text { practical assignments }\end{array}$ & $\begin{array}{c}\text { Average grade } \\
\text { for Design Intent }\end{array}$ \\
\hline Adaptive Expertise & Correlation & 0.175 & $0.386^{*}$ & $0.327^{*}$ & $0.395^{* *}$ \\
& Sig. (2-tailed) & 0.275 & 0.012 & 0.035 & 0.010 \\
\hline Multiple Perspectives & Correlation & 0.281 & 0.291 & 0.098 & 0.138 \\
& Sig. (2-tailed) & 0.075 & 0.061 & 0.537 & 0.385 \\
\hline Metacognition & Correlation & 0.031 & 0.279 & 0.143 & 0.146 \\
& Sig. (2-tailed) & 0.850 & 0.074 & 0.367 & 0.356 \\
\hline Goals and Beliefs & Correlation & 0.030 & 0.201 & $0.411^{* *}$ & $0.430^{* *}$ \\
& Sig. (2-tailed) & 0.853 & 0.202 & 0.007 & 0.005 \\
\hline Epistemology & Correlation & 0.175 & 0.191 & 0.083 & 0.150 \\
& Sig. (2-tailed) & 0.274 & 0.225 & 0.603 & 0.344 \\
\hline **. Correlation is significant at the 0.01 level (2-tailed). \\
*. Correlation is significant at the 0.05 level (2-tailed). \\
\hline
\end{tabular}

In the second year, a linear relation was noted in the results of the survey with 42 items between $\mathrm{AE}$ and the grades for theory, the average grades for practical assignments and the average grades for DI. With regard to the constructs, only 'goals and beliefs' show a linear relation with the average for practices and the average grade for DI.

The results of the correlations for multiple perspectives when comparing tables 1 and 2 are surprising. Our justification is that the 5 items of multiple perspectives are presented in a negative way in table 1 and the grades are therefore reversed, and 7 of the 11 items are negative in table 2 . In our opinion, there may be some students that have a tendency to give high grades, when what 
they are in reality giving is a low grade and therefore, the correlations are negative in table 1 on multiple perspectives.

\subsection{Survey results (annex 1). Adaptive expertise.}

In the first year, the initial population of the study numbered 78 students. The aim was to confirm whether students with a high degree of AE obtained better results than the students with a low degree, in relation to CAD. AE and its constructs were measured: Metacognition, Multiple Perspectives, and Goals and Beliefs.

Degrees of AE and its constructs were set in accordance with the 60/30 percentiles at High (H), Medium (M) and Low (L) and were contrasted with respect to the variables: grade for the conrod, average grade for practices and theory grade. In Table 3, the grades for the variables are between 0 and 10, indicating the standard error of the measurement between parentheses.

It may be observed that the group with high grades for metacognition has higher Average Grades for Practical assignments and for Theory than the group with low grades for metacognition and those differences in grades are significant.

Table 3. Comparison of AE with CAD (first year)

\begin{tabular}{|c|c|c|c|c|c|c|c|c|}
\hline \multirow{2}{*}{$\mathbf{A E}$} & \multirow{2}{*}{ VARIABLES } & \multicolumn{3}{|c|}{ Average (SE) } & \multirow{2}{*}{ Groups } & \multirow{2}{*}{ Normality } & \multirow{2}{*}{ TEST } & \multirow{2}{*}{ Sig. } \\
\hline & & $\mathbf{H}$ & $\mathbf{M}$ & $\mathbf{L}$ & & & & \\
\hline \multirow{3}{*}{ Degree AE } & Grade for the Conrod & $\begin{array}{c}5.59 \\
(0.343)\end{array}$ & $\begin{array}{c}5.65 \\
(0.317)\end{array}$ & $\begin{array}{c}5.52 \\
(0.332)\end{array}$ & \begin{tabular}{|l|} 
H-M \\
H-L \\
M-L
\end{tabular} & YES & HSD Tukey & $\begin{array}{l}0.989 \\
0.991 \\
0.964 \\
\end{array}$ \\
\hline & $\begin{array}{c}\text { Average grade } \\
\text { practical assignments }\end{array}$ & $\begin{array}{c}6.23 \\
(0.227)\end{array}$ & $\begin{array}{c}6.44 \\
(0.213)\end{array}$ & \begin{tabular}{|c|}
5.98 \\
$(0.257)$
\end{tabular} & H-M-L & NO & Kruskal-Wallis & 0.413 \\
\hline & Grade for Theory & $\begin{array}{c}4.86 \\
(0.318)\end{array}$ & $\begin{array}{c}4.84 \\
(0.378)\end{array}$ & \begin{tabular}{|c|}
4.73 \\
$(0.425)$
\end{tabular} & \begin{tabular}{|l|} 
H-M \\
H-L \\
M-L
\end{tabular} & YES & HSD Tukey & $\begin{array}{l}0.999 \\
0.969 \\
0.980 \\
\end{array}$ \\
\hline \multirow{3}{*}{$\begin{array}{l}\text { Degree } \\
\text { Metacognition }\end{array}$} & Grade for the Conrod & $\begin{array}{c}5.78 \\
(0.291)\end{array}$ & $\begin{array}{c}5.09 \\
(0.484)\end{array}$ & $\begin{array}{c}5.48 \\
(0.290)\end{array}$ & $\begin{array}{l}\text { H-M } \\
\text { H-L } \\
\text { M-L }\end{array}$ & YES & HSD Tukey & $\begin{array}{l}0.539 \\
0.755 \\
0.827\end{array}$ \\
\hline & $\begin{array}{c}\text { Average grade } \\
\text { practical assignments }\end{array}$ & $\begin{array}{c}6.56 \\
(0.205)\end{array}$ & $\begin{array}{c}6.05 \\
(0.350)\end{array}$ & $\begin{array}{c}5.87 \\
(0.178)\end{array}$ & $\begin{array}{l}\text { H-M-L } \\
\text { H-M } \\
\text { H-L } \\
\text { M-L }\end{array}$ & $\begin{array}{c}\text { NO } \\
\text { NO } \\
\text { NO } \\
\text { YES }\end{array}$ & $\begin{array}{c}\text { Kruskal-Wallis } \\
\text { Mann-Whitney } \\
\text { Mann-Whitney } \\
\text { t-Student }\end{array}$ & $\begin{array}{l}\mathbf{0 . 0 1 5} \\
0.121 \\
\mathbf{0 . 0 0 6} \\
0.245 \\
\end{array}$ \\
\hline & Grade for Theory & $\begin{array}{c}5.29 \\
(0.279)\end{array}$ & $\begin{array}{c}4.46 \\
(0.795)\end{array}$ & \begin{tabular}{|c|}
4.32 \\
$(0.318)$
\end{tabular} & $\begin{array}{l}\text { H-M-L } \\
\text { H-M } \\
\text { H-L } \\
\text { M-L } \\
\end{array}$ & $\begin{array}{l}\text { NO } \\
\text { NO } \\
\text { YES } \\
\text { NO }\end{array}$ & $\begin{array}{c}\text { Kruskal-Wallis } \\
\text { Mann-Whitney } \\
\text { t-Student } \\
\text { Mann-Whitney }\end{array}$ & $\begin{array}{l}\mathbf{0 . 0 2 2} \\
0.077 \\
\mathbf{0 . 0 2 5} \\
0.902 \\
\end{array}$ \\
\hline \multirow{3}{*}{$\begin{array}{l}\text { Degree } \\
\text { Multiple } \\
\text { Perspectives }\end{array}$} & Grade for the Conrod & $\begin{array}{c}5.58 \\
(0.328)\end{array}$ & $\begin{array}{c}5.27 \\
(0.333)\end{array}$ & \begin{tabular}{|c|}
5.92 \\
$(0.317)$
\end{tabular} & H-M-L & NO & Kruskal-Wallis & 0.370 \\
\hline & $\begin{array}{c}\text { Average grade } \\
\text { practical assignments }\end{array}$ & $\begin{array}{c}5.98 \\
(0.189)\end{array}$ & $\begin{array}{c}6.24 \\
(0.259)\end{array}$ & \begin{tabular}{|c|}
6.56 \\
$(0.256)$
\end{tabular} & \begin{tabular}{|l|} 
H-M \\
H-L \\
M-L \\
\end{tabular} & YES & HSD Tukey & $\begin{array}{ll}0.711 \\
0.186 \\
0.618 \\
\end{array}$ \\
\hline & Grade for Theory & $\begin{array}{c}4.43 \\
(0.294)\end{array}$ & $\begin{array}{c}4.80 \\
(0.325)\end{array}$ & $\begin{array}{c}5.39 \\
(0.469)\end{array}$ & $\begin{array}{l}\text { H-M } \\
\text { H-L } \\
\text { M-L }\end{array}$ & YES & HSD Tukey & $\begin{array}{l}0.744 \\
0.136 \\
0.530 \\
\end{array}$ \\
\hline \multirow{3}{*}{$\begin{array}{l}\text { Degree Goals } \\
\text { and Beliefs }\end{array}$} & Grade for the Conrod & $\begin{array}{c}5.53 \\
(0.340)\end{array}$ & $\begin{array}{c}5.50 \\
(0.345)\end{array}$ & $\begin{array}{c}5.76 \\
(0.311)\end{array}$ & \begin{tabular}{|l|} 
H-M \\
H-L \\
M-L
\end{tabular} & YES & HSD Tukey & $\begin{array}{l}0.998 \\
0.873 \\
0.857\end{array}$ \\
\hline & $\begin{array}{c}\text { Average grade } \\
\text { practical assignments }\end{array}$ & $\begin{array}{c}6.37 \\
(0.209)\end{array}$ & $\begin{array}{c}6.01 \\
(0.260)\end{array}$ & $\begin{array}{c}6.26 \\
(0.236)\end{array}$ & $\begin{array}{l}\text { H-M } \\
\text { H-L } \\
\text { M-L }\end{array}$ & YES & HSD Tukey & $\begin{array}{l}0.518 \\
0.941 \\
0.762\end{array}$ \\
\hline & Grade for Theory & $\begin{array}{c}4.78 \\
(0.346)\end{array}$ & $\begin{array}{c}4.86 \\
(0.344)\end{array}$ & $\begin{array}{c}4.82 \\
(0.415)\end{array}$ & $\begin{array}{l}\text { H-M } \\
\text { H-L } \\
\text { M-L }\end{array}$ & YES & HSD Tukey & $\begin{array}{l}0.986 \\
0.997 \\
0.996\end{array}$ \\
\hline
\end{tabular}




\subsection{Survey results (annex 2). Adaptive expertise.}

The results of the exercises in the second year appear in table 4. DI was introduced at the beginning of the year, both the DI and the CAD evaluations are shown in figures 1 and 4, and the survey shown in annex 2 was used.

The following may be seen from table 4: the differences are significant to 95\% between groups $\mathrm{H}$ $\mathrm{L}$ and M-L in Metacognition with regard to the grades for theory; the differences are significant to 95\% between groups H-L in Goals and Beliefs with regard to the average grades for practical assignments; the differences are significant to $90 \%$ between groups $\mathrm{H}-\mathrm{L}$ for $\mathrm{AE}$ with regard to the average grades for practices and theory; and to 95\% between groups $\mathrm{H}$ and $\mathrm{M}$ for the grades for the conrod exercise.

Likewise, with the objective of greater discrimination of the DI, solely the grades for DI in the different exercises are identified and grouped independently in this second year. The grades are given in table 5 out of 10 points as a sum of the average grades in the different DI-related exercises.

Table 4. Comparison of AE with CAD (second year)

\begin{tabular}{|c|c|c|c|c|c|c|c|c|}
\hline \multirow{2}{*}{$\mathbf{A E}$} & \multirow{2}{*}{ VARIABLES } & \multicolumn{3}{|c|}{ Average (SE) } & \multirow{2}{*}{ Groups } & \multirow{2}{*}{ Normality } & \multirow{2}{*}{ TEST } & \multirow{2}{*}{ Sig. } \\
\hline & & H & M & $\mathbf{L}$ & & & & \\
\hline \multirow{3}{*}{ Degree AE } & Grade for the Conrod & $\begin{array}{c}8.06 \\
(0.322)\end{array}$ & $\begin{array}{c}6.65 \\
(0.559)\end{array}$ & $\begin{array}{c}7.08 \\
(0.564)\end{array}$ & $\begin{array}{l}\text { H-M-L } \\
\text { H-M } \\
\text { H-L } \\
\text { M-L } \\
\end{array}$ & $\begin{array}{l}\text { NO } \\
\text { NO } \\
\text { NO } \\
\text { YES }\end{array}$ & $\begin{array}{c}\text { Kruskal-Wallis } \\
\text { Mann-Whitney } \\
\text { Mann-Whitney } \\
\text { t-Student }\end{array}$ & $\begin{array}{l}0.099 \\
\mathbf{0 . 0 4 2} \\
0.181 \\
0.594 \\
\end{array}$ \\
\hline & $\begin{array}{c}\text { Average grade } \\
\text { practical assignments }\end{array}$ & $\begin{array}{c}6.75 \\
(0.334)\end{array}$ & $\begin{array}{c}5.46 \\
(0.417)\end{array}$ & $\begin{array}{c}5.53 \\
(0.447)\end{array}$ & $\begin{array}{l}\text { H-M } \\
\text { H-L } \\
\text { M-L }\end{array}$ & YES & HSD Tukey & $\begin{array}{l}0.056 \\
0.083 \\
0.992\end{array}$ \\
\hline & Grade for Theory & $\begin{array}{c}5.25 \\
(0.364)\end{array}$ & $\begin{array}{c}4.11 \\
(0.509)\end{array}$ & $\begin{array}{c}3.56 \\
(0.728)\end{array}$ & \begin{tabular}{|l|} 
H-M \\
H-L \\
M-L \\
\end{tabular} & YES & HSD Tukey & \begin{tabular}{|l|}
0.256 \\
0.065 \\
0.763 \\
\end{tabular} \\
\hline \multirow{3}{*}{$\begin{array}{c}\text { Degree } \\
\text { Metacognition }\end{array}$} & Grade for the Conrod & $\begin{array}{c}7.42 \\
(0.407)\end{array}$ & $\begin{array}{c}7.5 \\
(0.580)\end{array}$ & $\begin{array}{c}6.89 \\
(0.519)\end{array}$ & H-M-L & NO & Kruskal-Wallis & 0.622 \\
\hline & $\begin{array}{c}\text { Average grade } \\
\text { practical assignments }\end{array}$ & $\begin{array}{c}6.35 \\
(0.342)\end{array}$ & $\begin{array}{c}6.01 \\
(0.456)\end{array}$ & $\begin{array}{c}5.26 \\
(0.451)\end{array}$ & \begin{tabular}{|l|} 
H-M \\
H-L \\
M-L \\
\end{tabular} & YES & HSD Tukey & \begin{tabular}{|l|}
0.811 \\
0.199 \\
0.490 \\
\end{tabular} \\
\hline & Grade for Theory & $\begin{array}{c}4.72 \\
(0.370)\end{array}$ & $\begin{array}{c}5.06 \\
(0.621)\end{array}$ & $\begin{array}{c}2.77 \\
(0.517)\end{array}$ & \begin{tabular}{|l|} 
H-M \\
H-L \\
M-L \\
\end{tabular} & YES & HSD Tukey & \begin{tabular}{|l|}
0.864 \\
$\mathbf{0 . 0 3 5}$ \\
$\mathbf{0 . 0 1 8}$ \\
\end{tabular} \\
\hline \multirow{3}{*}{$\begin{array}{c}\text { Degree } \\
\text { Multiple } \\
\text { Perspectives }\end{array}$} & Grade for the Conrod & $\begin{array}{c}8 \\
(0.362) \\
\end{array}$ & $\begin{array}{c}7.05 \\
(0.603) \\
\end{array}$ & $\begin{array}{c}6.8 \\
(0.509) \\
\end{array}$ & H-M-L & NO & Kruskal-Wallis & 0.140 \\
\hline & $\begin{array}{c}\text { Average grade } \\
\text { practical assignments }\end{array}$ & $\begin{array}{c}6.35 \\
(0.349)\end{array}$ & $\begin{array}{c}5.43 \\
(0.486)\end{array}$ & $\begin{array}{c}6.05 \\
(0.430)\end{array}$ & $\begin{array}{l}\text { H-M } \\
\text { H-L } \\
\text { M-L }\end{array}$ & YES & HSD Tukey & $\begin{array}{l}0.292 \\
0.856 \\
0.570\end{array}$ \\
\hline & Grade for Theory & $\begin{array}{c}4.87 \\
(0.507)\end{array}$ & $\begin{array}{c}4.23 \\
(0.758)\end{array}$ & $\begin{array}{c}4.07 \\
(0.424)\end{array}$ & \begin{tabular}{|l|} 
H-M \\
H-L \\
M-L \\
\end{tabular} & YES & HSD Tukey & \begin{tabular}{|l|}
0.704 \\
0.527 \\
0.979 \\
\end{tabular} \\
\hline \multirow{3}{*}{$\begin{array}{l}\text { Degree Goals } \\
\text { and Beliefs }\end{array}$} & Grade for the Conrod & $\begin{array}{c}7.24 \\
(0.363) \\
\end{array}$ & $\begin{array}{c}7.58 \\
(0.480) \\
\end{array}$ & $\begin{array}{c}7.17 \\
(0.821) \\
\end{array}$ & H-M-L & NO & Kruskal-Wallis & 0.849 \\
\hline & $\begin{array}{c}\text { Average grade } \\
\text { practical assignments }\end{array}$ & $\begin{array}{c}6.48 \\
(0.328)\end{array}$ & $\begin{array}{c}6.03 \\
(0.398)\end{array}$ & $\begin{array}{c}4.96 \\
(0.527)\end{array}$ & \begin{tabular}{|l|} 
H-M \\
H-L \\
M-L \\
\end{tabular} & YES & HSD Tukey & \begin{tabular}{|l|}
0.672 \\
$\mathbf{0 . 0 4 0}$ \\
0.220 \\
\end{tabular} \\
\hline & Grade for Theory & $\begin{array}{c}4.58 \\
(0.410)\end{array}$ & $\begin{array}{c}4.6 \\
(0.593)\end{array}$ & $\begin{array}{c}3.77 \\
(0.763)\end{array}$ & \begin{tabular}{|l|} 
H-M \\
H-L \\
M-L \\
\end{tabular} & YES & HSD Tukey & \begin{tabular}{|l|}
1.000 \\
0.594 \\
0.615 \\
\end{tabular} \\
\hline \multirow{3}{*}{$\begin{array}{c}\text { Degree } \\
\text { Epistemology }\end{array}$} & Grade for the Conrod & $\begin{array}{c}7.58 \\
(0.528)\end{array}$ & $\begin{array}{c}7.31 \\
(0.379)\end{array}$ & $\begin{array}{c}7.05 \\
(0.681)\end{array}$ & \begin{tabular}{|l} 
H-M \\
H-L \\
M-L \\
\end{tabular} & YES & HSD Tukey & \begin{tabular}{|l}
0.914 \\
0.777 \\
0.934 \\
\end{tabular} \\
\hline & $\begin{array}{c}\text { Average grade } \\
\text { practical assignments }\end{array}$ & $\begin{array}{c}5.91 \\
(0.440)\end{array}$ & $\begin{array}{c}5.97 \\
(0.364)\end{array}$ & $\begin{array}{c}6.19 \\
(0.510)\end{array}$ & \begin{tabular}{|l|} 
H-M \\
H-L \\
M-L \\
\end{tabular} & YES & HSD Tukey & $\begin{array}{l}0.994 \\
0.904 \\
0.932 \\
\end{array}$ \\
\hline & Grade for Theory & $\begin{array}{c}5.14 \\
(0.521)\end{array}$ & $\begin{array}{c}3.51 \\
(0.409)\end{array}$ & $\begin{array}{c}5.02 \\
(0.682)\end{array}$ & $\begin{array}{l}\mathrm{H}-\mathrm{M} \\
\mathrm{H}-\mathrm{L} \\
\mathrm{M}-\mathrm{L}\end{array}$ & YES & HSD Tukey & $\begin{array}{l}0.055 \\
0.987 \\
0.126\end{array}$ \\
\hline
\end{tabular}


Table 5. Comparison of AE with Grade for Design Intent

\begin{tabular}{|c|c|c|c|c|c|c|c|}
\hline \multirow{2}{*}{ VARIABLES } & \multicolumn{3}{|c|}{ Average (SE) } & \multirow{2}{*}{ Groups } & \multirow{2}{*}{ Normality } & \multirow{2}{*}{ TEST } & \multirow{2}{*}{ Sig. } \\
\hline & $\mathbf{H}$ & $\mathbf{M}$ & $\mathbf{L}$ & & & & \\
\hline Degree AE & $\begin{array}{c}6.80 \\
(0.313)\end{array}$ & $\begin{array}{c}5.38 \\
(0.399)\end{array}$ & $\begin{array}{c}5.29 \\
(0.457)\end{array}$ & $\begin{array}{l}\text { H-M } \\
\text { H-L } \\
\text { M-L }\end{array}$ & YES & $\begin{array}{l}\text { HSD } \\
\text { Tukey }\end{array}$ & $\begin{array}{l}\mathbf{0 . 0 2 7} \\
\mathbf{0 . 0 2 1} \\
0.988\end{array}$ \\
\hline Degree Metacognition & $\begin{array}{c}6.19 \\
(0.265)\end{array}$ & $\begin{array}{c}6.04 \\
(0.522)\end{array}$ & $\begin{array}{c}5.21 \\
(0.538)\end{array}$ & $\begin{array}{l}\text { H-M } \\
\text { H-L } \\
\text { M-L }\end{array}$ & YES & $\begin{array}{l}\text { HSD } \\
\text { Tukey }\end{array}$ & $\begin{array}{l}0.962 \\
0.278 \\
0.431 \\
\end{array}$ \\
\hline $\begin{array}{l}\text { Degree Multiple } \\
\text { Perspectives }\end{array}$ & $\begin{array}{c}6.35 \\
(0.342)\end{array}$ & $\begin{array}{c}5.35 \\
(0.460)\end{array}$ & $\begin{array}{c}5.90 \\
(0.451)\end{array}$ & $\begin{array}{l}\mathrm{H}-\mathrm{M} \\
\mathrm{H}-\mathrm{L} \\
\mathrm{M}-\mathrm{L}\end{array}$ & YES & $\begin{array}{l}\text { HSD } \\
\text { Tukey }\end{array}$ & $\begin{array}{l}0.238 \\
0.704 \\
0.643\end{array}$ \\
\hline $\begin{array}{l}\text { Degree Goals and } \\
\text { Beliefs }\end{array}$ & $\begin{array}{c}6.49 \\
(0.337)\end{array}$ & $\begin{array}{c}5.79 \\
(0.412)\end{array}$ & $\begin{array}{c}4.96 \\
(0.476)\end{array}$ & $\begin{array}{l}\text { H-M } \\
\text { H-L } \\
\text { M-L }\end{array}$ & YES & $\begin{array}{l}\text { HSD } \\
\text { Tukey }\end{array}$ & $\begin{array}{l}0.386 \\
\mathbf{0 . 0 4 0} \\
0.400 \\
\end{array}$ \\
\hline Degree Epistemology & $\begin{array}{c}5.92 \\
(0.439)\end{array}$ & $\begin{array}{c}5.86 \\
(0.381)\end{array}$ & $\begin{array}{c}6.07 \\
(0.482)\end{array}$ & $\begin{array}{l}\text { H-M } \\
\text { H-L } \\
\text { M-L }\end{array}$ & YES & $\begin{array}{l}\text { HSD } \\
\text { Tukey }\end{array}$ & $\begin{array}{l}0.994 \\
0.970 \\
0.939\end{array}$ \\
\hline
\end{tabular}

The following may be seen from table 5: the differences between groups $\mathrm{H}-\mathrm{L}$ are significant to 95\% under the component Goals and Beliefs with regard to DI, and most importantly, there are significant differences of up to $95 \%$ at a general level between groups $\mathrm{H}-\mathrm{M}$ and $\mathrm{H}-\mathrm{L}$ of $\mathrm{AE}$ with regard to DI.

From our point of view, the improvement in the second-year results are principally due to having incorporated DI since the beginning of the course through the different exercises, to having evaluated DI in a larger number of exercises, and that the positive and negative questions are more balanced in the Fisher survey (Fisher and Peterson 2001) (24 negative items out of 42 items) than in the Peng survey (Peng et al. 2014) (13 negative items out of 17).

\subsection{Survey Results of annex 3. Analysis of responses to the questionnaire before and after modeling.}

Only the responses to the questions which provided relevant information were analyzed. The responses of the students were collected, analyzed, and classified as shown below in the tables. Two groups were formed: those who thought of that characteristic or quality (group 1) and those who did not (group 0), comparing the average grades of the two groups in the conrod exercise.

1: With regard to the question: what are the thought processes of students when they set themselves the task of modeling the conrod? The results are shown in table 6 . They include the number of students who think of that construct, the average grades in the exercise to model the conrod with a range of 10 points, and their standard error (SE).

The vast majority of the students considered the number of 'pieces of the part' or pieces into which the part should be divided, resulting in a significant difference of $95 \%$ in favor of those students who had thought of it. 
Table 6. Results of the variables of student thought processes

\begin{tabular}{|c|c|c|c|c|c|c|c|}
\hline \multicolumn{8}{|c|}{ Test for independent samples } \\
\hline \multirow{3}{*}{ Thinking process } & \multicolumn{4}{|c|}{ Group } & \multicolumn{3}{|c|}{ Comparative Test } \\
\hline & \multicolumn{2}{|l|}{0} & \multicolumn{2}{|l|}{1} & \multirow{2}{*}{ Name } & \multirow{2}{*}{ Statistic } & \multirow{2}{*}{ Sig. } \\
\hline & Avg. (SE) & $\mathrm{N}^{\circ}$ & Avg. (SE) & $\mathrm{N}^{\circ}$ & & & \\
\hline $\begin{array}{l}\text { Number of pieces } \\
\text { forming each part }\end{array}$ & $4.99 \quad(0.328)$ & 26 & $5.85 \quad(0.231)$ & 48 & t-Student & -2.170 & 0.033 \\
\hline How to start the design & $5.54(0.236)$ & 50 & $5.57 \quad(0.347)$ & 24 & t-Student & -0.091 & 0.928 \\
\hline Constructive elements & $5.42(0.235)$ & 55 & $5.91 \quad(0.318)$ & 19 & $\begin{array}{l}\text { U Mann- } \\
\text { Whitney }\end{array}$ & -0.806 & 0.420 \\
\hline Solid operations & $5.52(0.216)$ & 62 & $5.69 \quad(0.436)$ & 12 & t-Student & -0.317 & 0.752 \\
\hline Boolean operations & $5.43(0.221)$ & 62 & $6.15 \quad(0.315)$ & 12 & $\begin{array}{l}\text { U Mann- } \\
\text { Whitney }\end{array}$ & -1.285 & 0.199 \\
\hline Finality of the part & $5.64(0.202)$ & 66 & $4.81 \quad(0.646)$ & 8 & t-Student & 1.328 & 0.188 \\
\hline $\begin{array}{l}\text { Order in which } \\
\text { to model it }\end{array}$ & $5.52(0.204)$ & 67 & $5.82(0.649)$ & 7 & $\begin{array}{l}\text { U Mann- } \\
\text { Whitney }\end{array}$ & -0.296 & 0.767 \\
\hline In the form of a part & $5.57 \quad(0.202)$ & 68 & $5.33 \quad(0.741)$ & 6 & t-Student & 0.326 & 0.745 \\
\hline Possible symmetries & - & 71 & - & 3 & - & - & - \\
\hline $\begin{array}{l}\text { Applying class } \\
\text { knowledge }\end{array}$ & -- & 72 & -- & 2 & - & - & - \\
\hline How will it be graded & $-\quad-$ & 73 & - & 1 & - & - & - \\
\hline Difficulties of the part & - & 73 & - & 1 & - & - & - \\
\hline
\end{tabular}

There were 6 students who said they thought of the 'Form of a part' and 48 students who said they thought of the 'Number of pieces of the parts'. And only 2 of the 6 students said that they thought of both characteristics. The two categories were not integrated into only one because we considered that the students, in accordance with their responses, could have different levels of abstract thought. It is a different thing to think in a general form of the whole part that is at a higher level of abstraction, where it can be thought of as modeled by solids or by surfaces, than to think of the pieces that form the part, which is at a lower level of abstraction.

It may be mentioned that the 8 students who thought of the finality of the part obtained lower grades than the students who gave no consideration to the finality of the part. Of those 8 students, 4 prepared no skeleton and 3 offered no division of the part into its constituent pieces, and it should be remembered that both tasks were awarded points in the evaluation of the part.

There were four qualities or characteristics that were most prominent in the thought processes of the students: the number of pieces of the parts, the constructive elements, the solid operations and the Boolean operations. The quality 'how to start the design' was excluded, as it is supposed that everybody should think of it.

The students were grouped into the following three groups, with the aim of continuing to study the importance of the different qualities that occupy their thought processes:

- Group 1 (Four basic characteristics): formed of the students that solely think of some of the basic aforementioned characteristics.

- Group 2 (Other characteristics): formed of the students who only think of some characteristics other than the four basic ones.

- Group 3 (Both groups): formed of the students who think of at least one characteristic of those from the first two groups. 
In table 7, the four basic characteristics may be seen that are more important than all the others, with the purpose of maintaining the DI in CAD, as the grades of group 1 are better than those of group 2 in the grades for the conrod (out of 10 points). It is also observed that the students from group 3 obtained better grades than those of group 1 and those of group 2. Therefore, to think of more than one characteristic improves DI. This last commentary leads us to conjecture that thinking from different points of view (in other words, holding multiple perspectives) improves $\mathrm{DI}$ in $\mathrm{CAD}$.

Table 7. Results of the comparison of means for the conrod

\begin{tabular}{|c|c|c|c|c|c|c|}
\hline \multicolumn{7}{|c|}{ Test for independent samples } \\
\hline \multirow{2}{*}{ Thought Processes } & \multirow[b]{2}{*}{ Group } & \multirow[b]{2}{*}{$\mathrm{N}$} & \multirow[b]{2}{*}{ Avg. (SE) } & \multicolumn{3}{|c|}{ Comparative Test } \\
\hline & & & & Name & Statistic & Sig. \\
\hline \multirow{2}{*}{ Four Basic / Others } & 1 & 32 & $5.54(0.288)$ & \multirow{2}{*}{ t-Student } & \multirow{2}{*}{1.893} & \multirow{2}{*}{0.064} \\
\hline & 2 & 18 & $4.60 \quad(0.424)$ & & & \\
\hline \multirow{2}{*}{ Both / Others } & 3 & 22 & $6.51(0.214)$ & \multirow{2}{*}{ t-Student } & \multirow{2}{*}{4.033} & \multirow{2}{*}{0.000} \\
\hline & 2 & 18 & $4.60 \quad(0.424)$ & & & \\
\hline \multirow{2}{*}{ Four Basic / Both } & 1 & 32 & $5.54(0.288)$ & \multirow{2}{*}{ t-Student } & \multirow{2}{*}{-2.492} & \multirow{2}{*}{0.016} \\
\hline & 3 & 22 & $6.51(0.214)$ & & & \\
\hline
\end{tabular}

2: To the question: Does the object that you are going to model appear familiar insofar as the way it functions? In the first row of table 8, the students are grouped in relation to whether or not they believe they are familiar with the part. From among the 68 students who were familiar with the part, 19 students stated that they knew that the function of the part is to transform a rotating into a reciprocating motion. A correct description of the function of the part represents a deeper degree of knowledge than mere familiarity with its function. We grouped these to test the influence of the function on DI.

Table 8. Results of the comparison of means for the conrod

\begin{tabular}{|c|c|c|c|c|c|c|c|}
\hline \multicolumn{8}{|c|}{ Test for independent samples } \\
\hline & \multicolumn{4}{|c|}{ Group } & \multicolumn{3}{|c|}{ Comparative Test } \\
\hline & \multicolumn{2}{|l|}{0} & \multicolumn{2}{|l|}{1} & \multirow{2}{*}{ Name } & \multirow{2}{*}{ Statistic } & \multirow{2}{*}{ Sig. } \\
\hline & Avg. (SE) & $\mathrm{N}$ & Avg. (SE) & $\mathrm{N}$ & & & \\
\hline Familiarity & $5.33(0.784)$ & 6 & $5.57 \quad(0.201)$ & 68 & t-Student & -0.326 & 0.745 \\
\hline Function & $5.28(0.230)$ & 54 & $6.47 \quad(0.252)$ & 19 & t-Student & -3.505 & 0.001 \\
\hline
\end{tabular}

Observing table 8, it may be affirmed at a confidence level of 99\% that knowledge of the function of the part to be modeled improved the grades given for CAD models that complied with the DI.

The results of the row 'function' in table 8 might appear to enter into contradiction with the results of the row 'finality of the part' in table 6, even though that is not so. There are 8 students who thought of the finality of the part first of all, according to the responses, in table 6 , to the question on what the thought processes of the students were when they started to model the part. The 
students who were able to describe the function of the part, who were not the same students as those who thought of the function of the part when starting the modeling exercise, are accounted for in table 8 .

3: Responses to the question: if you are familiar with the object that you are going to model, will it be easier for you to model it and if so why? The main responses are given in table 9, where it may be seen that the students affirm that familiarity with the conrod has helped them in a simple way to identify the pieces into which the part should be divided, and as we saw earlier on, that aspect is fundamental to manage to transfer the DI in CAD.

Table 9. How does familiarity with the object help when modeling?

\begin{tabular}{|c|c|c|c|c|c|c|c|c|c|}
\hline \multicolumn{10}{|c|}{ Test for independent samples } \\
\hline & \multicolumn{6}{|c|}{ Group } & \multicolumn{3}{|c|}{ Comparative Test } \\
\hline & \multicolumn{3}{|c|}{0} & \multicolumn{3}{|c|}{1} & \multirow{2}{*}{ Name } & \multirow{2}{*}{ Statistic } & \multirow[b]{2}{*}{ Sig. } \\
\hline & Avg & $(\mathrm{SE})$ & $\mathrm{N}$ & Avg & $(\mathrm{SE})$ & $\mathrm{N}$ & & & \\
\hline Identifying pieces & 5.36 & (0.223) & 59 & 6.30 & $(0.323)$ & 15 & t-Student & -2.000 & 0.049 \\
\hline Facilitates design & 5.53 & $(0.216)$ & 61 & 5.63 & $(0.451)$ & 13 & t-Student & -0.207 & 0.837 \\
\hline Flexible model & 5.47 & $(0.211)$ & 66 & 6.19 & $(0.374)$ & 8 & t-Student & -1.154 & 0.252 \\
\hline Simple part & 5.49 & $(0.207)$ & 68 & 6.21 & $(0.384)$ & 6 & t-Student & -1.014 & 0.314 \\
\hline $\begin{array}{l}\text { Name of pieces of } \\
\text { the parts }\end{array}$ & 5.53 & $(0.202)$ & 70 & 5.87 & $(0.591)$ & 4 & t-Student & -0.402 & 0.689 \\
\hline Where to start & 5.55 & $(0.202)$ & 70 & 5.56 & $(0.695)$ & 4 & t-Student & -0.019 & 0.985 \\
\hline
\end{tabular}

4: Responses to the question: How have you overcome the difficulties that emerged during the modeling process? The strategies used to overcome the various difficulties that were found may be seen in table 10 .

Table 10. Strategies used to overcome the difficulties

\begin{tabular}{|c|c|c|c|c|c|c|c|}
\hline \multicolumn{8}{|c|}{ Test for independent samples } \\
\hline \multirow{3}{*}{ Strategy } & \multicolumn{4}{|c|}{ Group } & \multicolumn{3}{|c|}{ Comparative Test } \\
\hline & \multicolumn{2}{|l|}{0} & \multicolumn{2}{|l|}{1} & \multirow{2}{*}{ Name } & \multirow{2}{*}{ Statistic } & \multirow{2}{*}{ Sig. } \\
\hline & Avg. (SE) & $\mathrm{N}$ & Avg. (SE) & $\mathrm{N}$ & & & \\
\hline New alternatives & $4.99(0.244)$ & 21 & $5.90(0.230)$ & 50 & U Mann-Whitney & -2.669 & 0.008 \\
\hline Consulting notes & $5.48 \quad(0.212)$ & 63 & $5.91(0.484)$ & 11 & t-Student & -0.779 & 0.439 \\
\hline Internet & $5.64(0.209)$ & 66 & $4.43(0.260)$ & 7 & U Mann-Whitney & -2.299 & 0.022 \\
\hline Previous practice & $5.49(0.211)$ & 67 & $6.11(0.288)$ & 7 & t-Student & -0.934 & 0.353 \\
\hline Fellow students & $5.57(0.206)$ & 68 & $5.25(0.528)$ & 6 & t-Student & 0.454 & 0.651 \\
\hline Starting again & $5.49(0.202)$ & 69 & $6.35(0.620)$ & 5 & U Mann-Whitney & -1.197 & 0.231 \\
\hline
\end{tabular}

The responses to the open-ended question shown above could be multiple. For example, we were able to confirm, after reviewing the reply sheets of the students, that 3 of the 5 students who used the strategy 'starting again' were also included in the 'new alternatives'. One student answered the question 'Going back and proposing it in another way' but the answer of another student was 'Deleting and returning to the origin of the problem'. In the second case, there is no inference that the student may have employed a new alternative. For example, errors can often exist in the 
sketches, although the location of the error is not found. The solution is to delete the sketch and to prepare it again, although that in itself will not mean using a new alternative.

The students who employed the strategy 'starting again' obtained the best results (6.35 points for the conrod). But there were only five that is not a significant number. It may be remarked that among the five students, 3 were also included in 'new alternatives' with an average grade of 7.33 and the two who were not included in it had an average score of 4.88. This high grade of 6.35 was due more to three students who were also included in 'new alternatives'.

The search for new alternatives to resolve the problems, improves the result in a significant way by $99 \%$ in CAD. Remember that the use of new alternatives is a characteristic of a person with multiple perspectives and, therefore, multiple perspectives in some way improve the results for DI.

It appears that a good strategy is to know what has not to be done when modeling a part. Mandorli and Otto (2013) sustained that so-called negative knowledge is a form of meta-knowledge revealing a regulative impact on positive knowledge. He also affirmed that negative knowledge is an element of strategic knowledge that restricts actions in critical situations that would otherwise lead to errors and mistakes. This negative knowledge may be achieved through a set of rules that the teacher has previously indicated and which Mandorli defined as 'The Concept of Feature Deficiency' (such as for example deficiencies in the type of feature, shape, and dimensions, and restrictions on the features or feature sequences) or through the negative experiences of the student. When not using these deficiencies, we avoid certain difficulties that arise when altering the CAD model and, in consequence, we improve the transfer of the DI.

Otto and Mandorli (2017) proposed the use of positive knowledge at the start of the course for beginners in solid modeling through the use of a set of rules, tutorials, and good practical exercises; and, subsequently, when modeling surfaces in hybrid modeling, to use the so-called strategy of negative knowledge linked to positive knowledge. In the second case, three elements should be kept in mind when selecting the surface modeling strategy: the tasks to carry out for designing the surface, a set of rules on good practice, and a set of deficiencies that will have to be avoided. All of that supports the development of $\mathrm{AE}$ in student $\mathrm{CAD}$ learning processes.

Nevertheless, it is interesting to highlight that those students who searched for the solution in Internet obtained worse grades, in a statistically significant way with a confidence interval of $95 \%$. One explanation may be that command-based learning is more prevalent in Internet, while a strategic-learning methodology is used in the classroom, through a set of CAD design rules that are intended to maintain DI in CAD modeling.

\subsection{Results of the survey of annex 3. Analysis of $\mathrm{AE}$ in the pre and post-modeling questionnaire.}

In the first year, the students were classified by their $\mathrm{AE}$ abilities and $\mathrm{AE}$ constructs through their responses to the open-ended questions in the survey, which were compared with the grades for the conrod exercises, to test their relation with DI. The method proposed by Liu et al. (2015) was 
applied to classify the responses to the open-ended questions given in annex 3, with the purpose of classifying the students in accordance with the AE constructs they use.

The following shows some examples of the responses given to the surveys before and after completing the modeling of the conrod, which are clear indications of mastery over one or another of the AE constructs:

- Various students analyzed the different operations that could be used to start their modeling, which is why they present multiple perspectives.

- One student described his way of working to model the part, so that he could avoid certain problems experienced in his earlier work. Another student was aware that he did not know all the program commands and he therefore adapted the design strategy to what he knew. This type of student, capable of recognizing the areas in which his knowledge is insufficient or capable of self-evaluation of his own understanding shows signs of metacognitive qualities.

- The organization of work that some students detail before beginning the modeling, in other words, the design of the roadmap, is associated with goals and beliefs.

- Within epistemology, we may classify certain students who affirm in their surveys that the thought processes of the teacher can guide them when completing their work.

When one of the AE constructs is identified in one or more of the responses from the student, the student is considered to present that construct of expertise. In table 11, the students that possess each quality of $\mathrm{AE}$ are shown in comparison with those without them. It may be observed that the students who presented these constructs obtained better grades in relation to the four constructs of AE for DI in the conrod exercise, moreover with differences at a statistically significant level for the constructs of multiple perspectives (90\%) and metacognition (95\%).

Table 11. Results of the variables of student thinking processes

\begin{tabular}{|c|c|c|c|c|c|c|c|c|}
\hline \multicolumn{9}{|c|}{ Test for independent samples } \\
\hline \multirow{3}{*}{ Adaptive Expertise } & \multicolumn{5}{|c|}{ Group } & \multicolumn{3}{|c|}{ Comparative Test } \\
\hline & \multicolumn{2}{|l|}{0} & \multicolumn{3}{|c|}{1} & \multirow{2}{*}{ Name } & \multirow{2}{*}{ Statistic } & \multirow{2}{*}{ Sig. } \\
\hline & Avg. (SE) & $\mathrm{N}$ & Avg. & $(\mathrm{SE})$ & $\mathrm{N}$ & & & \\
\hline Multiple Perspectives & $(0.285)$ & 38 & 5.99 & $(0.224)$ & 35 & t-Student & -1.988 & 0.051 \\
\hline Metacognition & $(0.272)$ & 32 & 6.02 & $(0.250)$ & 42 & U Mann-Whitney & -2.973 & 0.003 \\
\hline Goals and Beliefs & $(0.363)$ & 26 & 5.69 & $(0.225)$ & 48 & t-Student & -1.021 & 0.311 \\
\hline Epistemology & $(0.236)$ & 56 & 6.07 & $(0.283)$ & 18 & t-Student & -1.544 & 0.127 \\
\hline
\end{tabular}

And, finally, in a comparison between the students who present $\mathrm{AE}$ and those who do not, the students were classified by how many of the AE qualities they possessed, from zero to four. From the graph in figure 6, it may be seen that the more AE constructs the students possess, the higher their grades in the conrod exercise.

In table 12, the data from figure 6 are compared by means of the Tukey-Kramer post-hoc multiple comparisons test. The result obtained is that the students who presented two or four of the AE constructs obtained better grades for their conrod models, and in a significant way, with regard to 
the students who presented no construct. Although the grades of the group that possessed three constructs of the expertise marked a tendency, those results were not significant.

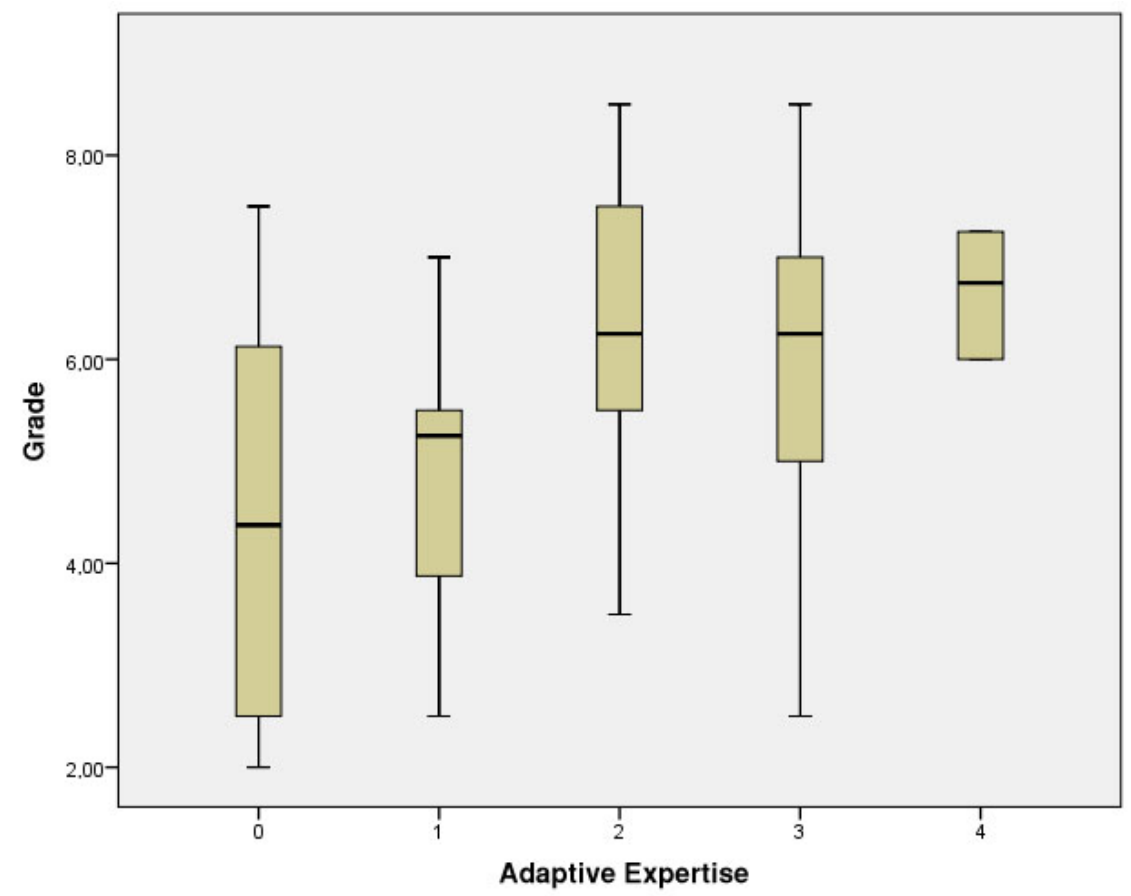

Fig. 6. Influence of the number of AE constructs on grading

Table 12. Multiple post-hoc comparisons: Tukey-Kramer test

\begin{tabular}{|c|c|c|c|c|c|c|}
\hline \multicolumn{7}{|c|}{$\begin{array}{l}\text { Dependent variable: Grade } \\
\text { HSD of Tukey }\end{array}$} \\
\hline \multirow{2}{*}{$\begin{array}{l}\text { (I) } \\
\text { Adaptive } \\
\text { Expertise }\end{array}$} & \multirow{2}{*}{$\begin{array}{l}\text { (J) Adaptive } \\
\text { Expertise }\end{array}$} & \multirow{2}{*}{$\begin{array}{l}\text { Difference } \\
\text { of means } \\
\text { (I-J) }\end{array}$} & \multirow{2}{*}{$\begin{array}{l}\text { Std. } \\
\text { Error }\end{array}$} & \multirow[b]{2}{*}{ Sig. } & \multicolumn{2}{|c|}{$\begin{array}{c}\text { Confidence interval } \\
\text { at } 95 \%\end{array}$} \\
\hline & & & & & Lower limit & Upper limit \\
\hline \multirow[t]{4}{*}{$0(\mathrm{~N}=8)$} & $1(\mathrm{~N}=19)$ & -0.444 & 0.620 & 0.952 & -2.182 & 1.294 \\
\hline & $2(\mathrm{~N}=22)$ & -1.767 & 0.607 & 0.038 & -3.470 & -0.065 \\
\hline & $3(\mathrm{~N}=17)$ & -1.460 & 0.631 & 0.153 & -3.227 & 0.308 \\
\hline & $4(N=6)$ & -2.229 & 0.794 & 0.050 & -4.456 & -0.002 \\
\hline
\end{tabular}

\section{CONCLUSIONS AND FUTURE WORK}

Following the review of the literature, we can affirm that the industry needs to reuse CAD models and, in consequence, universities should instruct their students in CAD, bearing in mind that the CAD models will be modified. So that the modifications may be introduced and so that the result maintains the DI, students need to be instructed through exercises on flexible and robust use of CAD, in which the students themselves should modify different CAD models. From this point of view, strategic learning should acquire increasing importance as opposed to command-based learning. 
The results of investigating AE differed in accordance with whether the surveys in annex 1 , annex 2 or the questionnaire in annex 3 were administered. The justification that we found, as stated by Bohle et al. (2016) is that no instrument exists that provides a good operationalization of the theoretical construct. As Bohle et al. (2016) indicated, all the tools used to measure AE fail in at least one construct. It may also be indicated that the Fisher survey is one of the two best designed to measure AE in a general way (without itemizing each of its four constructs). Below, we have set out the different conclusions of the results that have been significant in accordance with the year and the tool that was used:

- First year, using the questionnaire of annex 3

The aspects about which students think most before modeling a part are: 1) number of pieces of the part; 2) constructive elements to use; 3) which are the solid operations to use; 4) which Boolean operations to use; and, 5) the final purpose of the part. The students who thought of some of these aspects obtained better results for DI in their CAD exercises. It may also be said, in general terms, that the students who thought of various aspects obtained better results than those who only thought of one.

When confronted with the modeling of a 3D part, the correct division of the part into 'pieces of the parts' gives the model greater quality for its subsequent reutilization. Nevertheless, the basic or tangible aspects in the design are not the only aspects that should be taken into account, as the modeling process in global terms should also be considered.

Understanding the function of the part that is going to be modeled in CAD facilitates the identification of the pieces into which the part will be divided and the designs are in consequence more flexible and robust.

Strategic learning is considered more suitable than the command-based instruction found on Internet, since those students who attempted to solve their difficulties with the help of the Internet obtained worse results.

The students who thought of solving the problems by searching for new alternatives to overcome the difficulties in CAD obtained better results for DI. Remember that the use of new alternatives is a characteristic of a person with multiple perspectives and, therefore, multiple perspectives in some way improve the results of DI.

In broad terms, the AE helps in 3D modeling; at least two of the constructs are necessary to achieve a good modeling process.

- First year, using the survey from annex 1.

The metacognition construct of AE is a quality that improves the results of CAD at $\alpha<0.05$.

- Second year, using the survey from annex 2.

The students with higher AE obtained better results than those with lower AE with $\alpha<0.1$ in average grades for practical assignments and for theory; and therefore, for CAD. The 
students that developed greater metacognition obtained better grades in the theoretical concepts of CAD, at $\alpha<0.05$, than those whose metacognition was less developed. The students with a better developed 'goals and beliefs' component obtained better grades in the different CAD practices, at $\alpha<0.05$.

If we only study DI in CAD, then those students who had a better developed 'goals and beliefs' component applied DI better in CAD than those students who had developed that component less, at $\alpha<0.05$. And more importantly, those students who had better developed AE, applied DI better in CAD than the other students, at $\alpha<0.05$.

Finally, it is worth adding that it is necessary to investigate techniques that strengthen the AE, as the importance of exercising this quality has clearly been demonstrated.

\section{REFERENCES}

Aldaz Herrera, Nelson Marcelo. La Metacognición en la educación [Metacognition in education]. Monografias.com $\quad$ S.A. $2006 \quad$ [cited 05.02.18. Available from http://www.monografias.com/trabajos34/metacognicion-escuela/metacognicion-escuela.shtml.

Alducin-Quintero, G., A. Rojo, F. Plata, A. Hernández, and M. Contero. 2012. 3D model annotation as a tool for improving design intent communication: A case study on its impact in the engineering change process. Paper read at Proceedings of the ASME Design Engineering Technical Conference, 12 August at Chicago, IL; USA.

Bhavnani, Suresh K. , Frederick Reif, and Bonnie E. John. 2001. Beyond Command Knowledge: Identifying and Teaching Strategic Knowledge for Using Complex Computer Applications Paper read at Conference on Human Factors in Computing Systems, 03.01.01, at Seattle, WA, USA

Bodein, Yannick, Bertrand Rose, and Emmanuel Caillaud. 2013. "A roadmap for parametric CAD efficiency in the automotive industry." Computer-Aided Design no. 45 (10):1198-1214. doi: 10.1016/j.cad.2013.05.006.

Bodein, Yannick, Bertrand Rose, and Emmanuel Caillaud. 2014. "Explicit reference modeling methodology in parametric CAD system." Computers in Industry no. 65 (1):136-147. doi: 10.1016/j.compind.2013.08.004.

Bohle Carbonell, K., K. D. Könings, M. Segers, and J. J. van Merriënboer. 2016. "Measuring adaptive expertise: development and validation of an instrument." European Journal of Work and Organizational Psychology no. 25 (2):167-180.

Brophy, Sean, Lynn Hodge, and John Bransford. 2004. Adaptive Expertise: Beyond Apply Academic Knowledge Paper read at 34th ASEE/IEEE Frontiers in Education Conference (FIE), October 2023, at Savannah, GA (USA).

Camba, Jorge, Manuel Contero, Johnson Michael, and Pedro Company. 2014. "Extended 3D annotations as a new mechanism to explicitly communicate geometric design intent and increase CAD model reusability." Computer-Aided Design no. 57:61-73. doi: 10.1016/j.cad.2014.07.001.

Company, P., M. Contero, J. Otey, J. D. Camba, M. J. Agost, and D. Pérez-López. 2017. "Web-Based System for Adaptable Rubrics: Case Study on CAD Assessment." Educational Technology \& Society no. 20 (3):24-41.

Contero, Manuel. Gestión de anotaciones 3D sobre modelos CAD para mejorar el proceso de diseño en ambientes industriales y arquitectónicos [cited 15.12.17. Available from http://www.labhuman.com/es/node/800.

Chester, Ivan 2007. "Teaching for CAD expertise." International Journal of Technology and Design Education no. 17:23-35. doi: 10.1007/s10798-006-9015-z.

Fisher, Frank T., and Penelope L. Peterson. 2001. A Tool to Measure Adaptive Expertise in Biomedical Engineering Students. Paper read at 2001 American Society for Engineering Education Annual Conference \& Exposition, June, at Albuquerque, New Mexico.

Hartman, N. W. 2004. "The Development of Expertise in the Use of Constraintbased CAD Tools: Examining Practicing Professionals." Engineering Design Graphics Journal no. 68 (2):14-26. 
Hartman, N. W. 2005. "Defining Expertise in the Use of Constraint-based CAD Tools by Examining Practicing Professionals " Engineering Design Graphics Journal no. 69 (1):6-15.

Hatano, Giyoo, and Kayoko Inagaki. 1986. "Two courses of expertise." In Research and clinical center for child development. Annual Report, edited by Harold W. ; Azuma Stevenson, Hiroshi; Hakuta, Kenji, 27-36. Hokkaido University Library: Hokkaido University Collection of Scholarly and Academic Papers : HUSCAP. Original edition, Child development and education in Japan. A series of books in psychology., (pp. 262-272). New York, NY, US: W H Freeman/Times Books/ Henry Holt \& Co, X, 315 pp.

Hofmann, M., G. Hann, S. E. Hudson, and J. Mankoff. 2018. Greater than the Sum of its PARTs: Expressing and Reusing Design Intent in 3D Models. Paper read at CHI Conference on Human Factors in Computing Systems, April, at Montreal, QC, Canada.

Jackson, C., and M. Buxton. 2007. The Design Reuse Benchmark Report. Seizing the Opportunity to Shorten Product Development. Boston: Aberdeen Group.

Liu, K., X. Peng, P. McGary, B. Yalvac, E. Ozturk, M.D. Johnson, and L. Valverde. 2015. "Integration of contextual exercises in computeraided design education." Computer-Aided Design and Applications no. 12 (sup1):13-21.

Mandorli, F., H. E. Otto, and R. Raffaeli. 2016. "Explicit 3D functional dimensioning to support design intent representation and robust model alteration." Computer-Aided Design and Applications no. 13 (1):108-123. doi: 10.1080/16864360.2015.1059201.

Mandorli, Ferruccio, and Harald E. Otto. 2013. "Negative Knowledge and a Novel Approach to Support MCAD Education." Computer-Aided Design and Applications no. 10 (6):1007-1020. doi: 10.3722/cadaps.2013.1007-1020

McKenna, Ann F. 2007. "An Investigation of Adaptive Expertise and Transfer of Design Process Knowledge." Journal of Mechanical Design no. 129 (7): 730-734. doi: 10.1115/1.2722316.

Otey, J., P. Company, M. Contero, and J. Camba. 2014. A review of the design intent concept in the context of CAD model quality metrics. Paper read at 121st ASEE Annual Conference \& Exposition, June 15-18, at Indianapolis, IN.

Otey, J., P. Company, M. Contero, and J. D. Camba. 2018. "Revisiting the design intent concept in the context of mechanical CAD education." Computer-Aided Design and Applications no. 15 (1):4760.

Otto, Harald E., and Ferruccio Mandorli. 2017. "Integration of negative knowledge into MCAD education to support competency development for product design." Computer-Aided Design and Applications no. 14 (3):269-283,. doi: 10.1080/16864360.2016.1240448.

Peng, Xiaobo, Prentiss McGary, Elif Ozturk, Bugrahan Yalvac, Michael Johnson, and Lauralee M. Valverde. 2014. "Analyzing Adaptive Expertise and Contextual Exercise in Computer-Aided Design." Computer-Aided Design and Applications no. 11 (5):597-607. doi: 10.1080/16864360.2014.902693.

Ramos, Basilio, Carlos Melgosa, and Raul Zamora. 2017. "Learning CAD at university through summaries of the rules of design intent." International Journal of Technology and Design Education no. 27 (3):481-498. doi: 10.1007/s10798-016-9358-z.

Rynne, A., and W. Gaughran. 2008. "Cognitive modeling strategies for optimum design intent in parametric modelling (PM)." Computers in Education Journal no. 18 (1):55-68.

Salehi, Vahid, and Chris McMahon. 2009. Action research into the use of parametric associative CAD systems in an industrial context. Paper read at 17th International Conference on Engineering Design, 24-27 August, at Palo Alto, CA, USA.

Salehi, Vahid, and Chris McMahon. 2011. "Development and application of an integrated approach for parametric associative CAD design in an industrial context." Computer-Aided Design and Applications no. 8 (2):225-236. doi: 10.3722/cadaps.2011.225-236.

Yang, Jeongsam, and Soonhung Han. 2006. "Repairing CAD model errors based on the design history." Computer-Aided Design no. 38 (6):627-640. doi: 10.1016/j.cad.2006.02.007.

Ye, Xiuzi, Wei Peng, Zhiyang Chen, and Yi-Yu Cai. 2004. "Today's students, tomorrow's engineers: an industrial perspective on CAD education." Computer-Aided Design no. 36 (14):1451-1460. doi: 10.1016/j.cad.2003.11.006. 
Annex 1. Survey on adaptive expertise (Peng et al. 2014)

SURVEY ON ADAPTIVE EXPERTISE

\section{Personal information:}

- Surname and Name:

Sex: Age:

- Previous studies (vocational training or Baccalaureate):

\section{-Previous knowledge}

- Have you had previous experience of 3D CAD? Y/N

- If yes, my general level of knowledge of 3D CAD is low/medium/high?

Answer on the Likert scale from 1 to $6(1=$ Disagree a lot, $6=$ Very much in agreement $)$

\begin{tabular}{|l|l|l|l|l|l|l|}
\hline - I am in contact with the industry and with mechanics & 1 & 2 & 3 & 4 & 5 & 6 \\
\hline
\end{tabular}

- I have some knowledge of manufacturing processes.

- Multiple perspectives
\begin{tabular}{|l|l|l|l|l|l|l|}
\hline $\begin{array}{l}\text { - There is usually one correct method with which to represent a } \\
\text { problem. }\end{array}$ & 1 & 2 & 3 & 4 & 5 & 6 \\
\hline - I tend to focus on a particular method to solve a problem. & 1 & 2 & 3 & 4 & 5 & 6 \\
\hline - I solve all the related problems in the same manner. & 1 & 2 & 3 & 4 & 5 & 6 \\
\hline $\begin{array}{l}\text { - When I solve a new problem, I always try to use the same } \\
\text { approach. }\end{array}$ & 1 & 2 & 3 & 4 & 5 & 6 \\
\hline - There is one best way to approach a problem. & 1 & 2 & 3 & 4 & 5 & 6 \\
\hline
\end{tabular}

- Metacognition
\begin{tabular}{|l|l|l|l|l|l|l|}
\hline - As I learn, I question my understanding of the new information. & 1 & 2 & 3 & 4 & 5 & 6 \\
\hline - I often try to monitor my understanding of the problem. & 1 & 2 & 3 & 4 & 5 & 6 \\
\hline $\begin{array}{l}\text { - As a student, I cannot evaluate my own understanding of new } \\
\text { material. }\end{array}$ & 1 & 2 & 3 & 4 & 5 & 6 \\
\hline $\begin{array}{l}\text { - I rarely monitor my own understanding while learning } \\
\text { something new. }\end{array}$ & 1 & 2 & 3 & 4 & 5 & 6 \\
\hline - I monitor my performance on a task. & 1 & 2 & 3 & 4 & 5 & 6 \\
\hline $\begin{array}{l}\text { - When I am working, I ask myself how I am doing and seek out } \\
\text { appropriate feedback. }\end{array}$ & 1 & 2 & 3 & 4 & 5 & 6 \\
\hline
\end{tabular}

- Goals and beliefs

- I feel uncomfortable when I cannot solve difficult problems. - I am afraid to try tasks that I do not think I will do well.

- You must have an innate talent for engineering, to become an expert in engineering.

- Experts in engineering are born with a natural talent for their field.

- When I struggle, I wonder if I have the intelligence to succeed in engineering.

- I feel uncomfortable when unsure if I doing a problem the right way.

Many thanks for your collaboration 
Annex 2. Survey on adaptive expertise (Fisher and Peterson 2001)

\title{
Personal information:
}

\section{SURVEY ON ADAPTIVE EXPERTISE}

\author{
Surname and Name:
}

Answer on the Likert scale from I to $6(1=$ Disagree a lot, $6=$ Very much in agreement $)$ 1. I create several models of an engineering problem to see which one I like best.

2. As I learn, I question my understanding of the new information.

3. I feel uncomfortable when I cannot solve difficult problems.

4. Knowledge that exists today may be replaced with a new understanding tomorrow.

5. Usually there is one correct method in which to represent a problem

6. I often try to monitor my understanding of the problem.

7. I am afraid to try tasks that I do not think I will do well.

8. Most knowledge that exists in the world today will not change.

9. When I consider a problem, I like to see how many different ways I can look at it.

10. As a student, I cannot evaluate my own understanding of new material.

11. Although I hate to admit it, I would rather do well in a class than learn a lot.

12. Scientists are always revising their view of the world around them.

13. I tend to focus on a particular model in which to solve a problem.

14. I rarely monitor my own understanding while learning something new.

15. One can increase their level of expertise in any area if they are willing to try.

16. Facts that are taught to me in class must be true.

17. I am open to changing my mind when confronted with an alternative viewpoint.

18. When I know the material, I can recognize areas where my understanding is incomplete.

19. Expertise can be developed through hard work.

20 . Existing knowledge in the world seldom changes.

21. I rarely consider other ideas after I have found the best answer.

22. I have difficulty in determining how well I understand a topic.

23. To become an expert in engineering, you must have an innate talent for engineering.

24. Challenge stimulates me.

25. I find additional ideas burdensome after I have found a way to solve the problem.

26. I monitor my performance on a task.

27. Experts in engineering are born with a natural talent for their field.

28. Scientific theory slowly develops as ideas are analyzed and debated.

29. For a new situation, I consider a variety of approaches until one emerges superior.

30. As I work, I ask myself how I am doing and seek out appropriate feedback.

31. Experts are born, not made.

32. Even if frustrated when working on a difficult problem, I can push on.

33. Scientific knowledge is developed by a community of researchers.

34. I solve all related problems in the same manner.

35. Poorly completing a project is not a sign of a lack of intelligence

36. When I solve a new problem, I always try to use the same approach.

37. Scientific knowledge is discovered by individuals.

38. When I struggle, I wonder if I have the intelligence to succeed in engineering.

39. There is one best way to approach a problem.

40. I seldom evaluate my performance on a task.

41. I feel uncomfortable when unsure if I am doing a problem the right way.

42. Progress in science is due mainly to the work of sole individual

Many thanks for your collaboration 
Annex 3. Pre- and post-modeling questionnaires on the connecting rod exercise (Peng et al. 2014)

SURNAME AND NAME:

\section{CONNECTING ROD EXERCISE}

To do the following exercise you should, in the first place, carefully read this document.

You should answer the first questionnaire before starting to model in 3D. During the 3D modeling process you should control the time spent on thinking about how to do the exercise and the total time used in doing it (including the time spent thinking). When the exercise has finished you should answer the second questionnaire.

Write you answers on this same document below each question.

\section{FIRST QUESTIONNAIRE}

1. What are the things you consider first when you are asked to model the connecting rod? Why?

2. Are you familiar with the way that the object functions that you are going to model?

3. What degree of importance do you attach to knowing the object that you are going to model?

4. If you are familiar with the object that you are going to model, will it be easier for you to model it? Why?

5. What difficulties do you think you will encounter during the modeling process?
a. How are you going to deal with those difficulties?
b. What strategies do you expect to use?

TIME SPENT THINKING

TIME SPENT DOING THE MODELING:

\section{SECOND QUESTIONNAIRE:}

1. Were the things that you thought of before starting to model the connecting rod helpful to you in the process? How and why?

2. What challenges did you encounter during the modeling process?

3. How did you overcome the challenges that you encountered during the modeling?

4. If you are familiar with the object, did it help you in the modeling process? How and why?

5. If you had to model the connecting rod again, would you do it in the same way?

6. If your answer is no, what would the main changes be that you would introduce?

Many thanks you for your participation. 